\title{
Pertumbuhan Biji Palem Putri (Veitchia merilli (beec) h.f. moors) pada Berbagai Media Tumbuhan
}

\author{
Nurul Sumiasri, Dody Priadi dan INK Kabinawa \\ Puslit Bioteknologi Lembaga Ilmu Pengetahuan Indonesia \\ Jl. Raya Bogor, Km 46.Cibinong 16911 \\ E-mail : nurulsumi@yahoo.com
}

\begin{abstract}
Growth of Chirstmas Palm Seeds (Veitchia merilli (Beec) H.F.Moors) on Several

Growth Media

Christmas Palm ( Veitchia meriilii (Becc) H.F Moors ) is important ornamental plant in the cities, so the study of seed germination for commercial purpose need to be conducted. The objective of this study was to know germination and growth of Christmas Palm on several media with certain plant growth regulator. This study at glass house was conducted to verify the growth of Christmas Palm on four differrent growt medium i.e. compost, sand, Latosol and red yellow Podzolic. The results showed that best media to support germination and growth of Christmas Palm during first three months was compost. Other medium, sand, latosol and red yellow podzolic did not stimulate germination and growth of Palm as good as compost.
\end{abstract}

Key words: Growth Media, Seed growth, Veitchia merillii.

\begin{abstract}
ABSTRAK
Palem putri (Veitchia merillii (Beec) H.F.Moors) adalah tanaman hias penting di kota-kota sehingga studi perkecambahan biji untuk tujuan komersil perlu dilakukan. Penelitian ini bertujuan untuk mengetahui perkecambahan dan pertumbuhan biji palem putri pada berbagai media tumbuh yang diberi zat pengatur tumbuh (ZPT). Penelitian di rumah kaca ini menguji empat jenis media tumbuh yaitu kompos, pasir, Latosol dan Podsolik merah kuning (PMK). Hasil studi menunjukkan bahwa media terbaik untuk perkecambahan dan pertumbuhan bibit palem putri adalah kompos. Media pasir, tanah Latosol maupun Podsolik merah kuning tidak mendukung perkecambahan dan pertumbuhan bibit sebaik kompos.
\end{abstract}

Kata kunci: Media tumbuh, Pertumbuhan biji, Veitchia merilii.

\section{PENDAHULUAN}

Palem putri (Veitchia merillii (Beec) H.F Moors) adalah jenis palem hias tropis yang banyak dibudidayakan sebagai penyusun taman maupun tanaman tepi jalan terutama di kota-kota. Perawakannya unik dan harganya pun relatif mahal jika dibandingkan dengan jenis palem lainnya, sehingga cukup mempunyai nilai ekonomi di pasaran tanaman hias. Palem ini bersifat kosmopolitan (Noad \& Birnie, 1992) dan dapat dijumpai di daerah Asia Tropik dan Selandia Baru. Pertumbuhan tanaman ini lambat tingginya dapat mencapai 20 meter serta memper banyak diri dengan biji yang bewarna merah dan panjangnya sekitar $2 \mathrm{~cm}$ (Noad \& Birnie, 1992). Biji palem putri akan berkecambah setelah 2-4 minggu (Warintek, 2010).

Palem ini dapat tumbuh di daerah gersang maupun subur dengan tingkat pertumbuhan yang berbeda tergantung dari tingkat kesuburan media pertumbuhannya, karena tanaman mempunyai tanggap fisiologis berbeda di setiap kondisi (Sutopo,1984; Lakitan, 1995). Di tanah yang subur pertumbuhannya lebih baik daripada di tanah yang gersang. Selain itu tanaman ini tidak suka genangan air. Atas dasar sifat agronomis tersebut jenis media perkecambahan diduga akan mempengaruhi persentase perkecambahan dan parameter tanaman 
lainnya. Peningkatan persentase perkecambahan juga diyakini dipengaruhi oleh adanya zat pengatur tumbuh (ZPT) eksogen yang dapat mempercepat pertumbuhan akar dan batang tanaman di pesemaian (Hartmann et al., 1990).

Untuk tujuan komersil, biji dapat dikecambahkan di dalam media yang mudah didapat di Jawa Barat seperti kompos, pasir serta tanah. Berdasarkan sifat fisik dan kimianya, biji akan lebih mudah berkecambah pada kompos (Darmawidjaya, 1997). Media pasir menurut Poincelot (1979) tidak mengandung unsur hara serta tidak memiliki kapasitas penyangga maupun kapasitas pertukaran kation tetapi porositasnya tinggi sehingga mudah sekali ditembus oleh akar. Tanah adalah media pertumbuhan alami yang memiliki karakteristik fisik dan kimia tergantung pada jenisnya. Dua jenis tanah yaitu Latosol dan PMK berpotensi sebagai media tanam karena jenis tanah tersebut tersebar luas di Jawa Barat sehingga mudah didapat, tetapi tanah ini relatif miskin akan unsur hara (Harjoewigeno; 1992). Dalam klasifikasi tanah terbaru, penamaan Latosol dan Ppodsolik merah kuning menurut Norsamsi (2006) kedua jenis tanah tersebut adalah termasuk ordo dan derivat dari Ultisol. Media pembibitan berupa kompos diyakini sebagai media yang relatif lebih baik karena mengandung sejumlah unsur hara makro dan mikro serta beraerasi baik. Sejalan dengan peningkatan nilai tambah ekonomis palem putri, penelitian ini dilakukan dengan tujuan untuk mengetahui pertumbuhan bibit palem pada berbagai jenis media perkecambahan.

\section{BAHAN DAN METODE}

Penelitian dilakukan di pesemaian Kebun Plasma Nutfah Tumbuhan dan Hewan Puslit Bioteknologi LIPI Cibinong, selama 4 bulan. Penelitian dilakukan didalam rumah kaca pada penyinaran 600 lux (yaitu pada jam 7.00 pagi, 2000 lux pada jam 12.00 siang dan 300 lux pada jam 4.00 sore).

Penelitian ini adalah suatu eksperimen tanpa rancangan dengan perlakuan empat jenis media tanam palem putri yaitu tanah Podsolik merah kuning, tanah Latosol, pasir dan kompos. Sebelum dan setelah perkecambahan, dilakukan pemberian zat pengatur tumbuh dengan konsentrasi dan dosis yang sama. Biji dibiarkan tumbuh sampai tiga bulan saat dilakukan pengukuran terhadap \% berkecambah, pertumbuhan daun, tinggi tanaman dan panjang akar. Penelitian dilakukan dengan ulangan sebanyak 3 kali.

Tanaman palem putri dikoleksi dari Kebun Botani Puspiptek Serpong. Biji palem putri dipanen pada waktu biji masak fisiologis. Media pasir diambil dari DAS Cisadane di daerah Serpong, Banten. Tanah Latosol (Ultisol) lapisan atas diambil dari daerah Nanggewer, Kecamatan Cibinong - Bogor. Tanah Podsolik merah kuning (Ultisol ) lapisan atas diambil dari daerah Haurbentes, kecamatan Jasinga - Bogor dan kompos yang terbuat dari serasah diperoleh dari Kebun Botani Puspiptek Serpong, kecamatan Serpong - Tanggerang - Banten. Zat pengatur tumbuh tanaman yang digunakan, diolah/dilengkapi dari bahan yang mengandung sitokinin, gandasil D dan Biomasa Chlorella pyrenoidosa strain lokal INK yang disediakan oleh Kabinawa dari Laboratorium Akuakultur Puslit Bioteknologi LIPI.

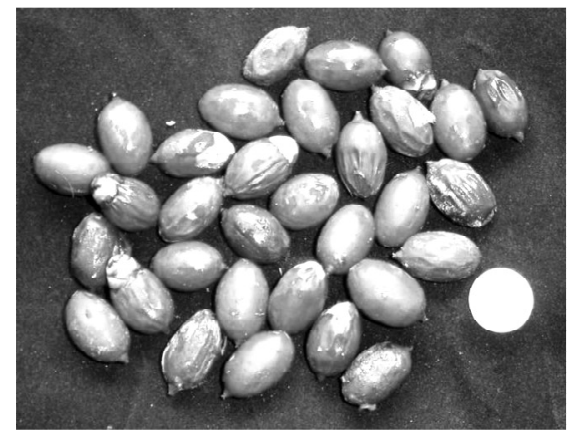

Gambar 1. Biji palem putri (Veitchia merillii (Beec)H.F Moors sebelum dikecambahkan

Biji-biji yang telah dibuang daging buahnya dibersihkan dengan air mengalir kemudian dikecambahkan pada gelas plastik yang berukuran volume $240 \mathrm{ml}$ berisi media yang sesuai dengan perlakuan penelitian dan diletakkan di rumah kaca di pesemaian kebun plasma nuftah Cibinong. Konsentrasi zat pengatur tumbuh adalah $2 \mathrm{mg} \mathrm{L}^{-1}$ yang diaplikasikan pada setiap media pertumbuhan sebelum perkecambahan dan setiap minggu sekali setelah tanaman berkecambah selama tiga bulan pertumbuhan. Dosis ZPT yang digunakan setiap aplikasi adalah $2 \mathrm{ml} \mathrm{L}^{-1}$ Selama perkecambahan berlangsung, biji disiram sebanyak 2 kali yaitu pagi dan sore hari. Selanjutnya bila biji sudah berkecambah, dilakukan penyiraman satu kali sehari sampai penelitian berakhir. Penyiraman diberikan pada tanaman sebanyak $22 \mathrm{ml}$ dan tidak mencapai kapasitas lapang agar akar bibit dapat mengambil udara dalam tanah terutama akar tanaman. 


\section{HASIL DAN PEMBAHASAN}

Persentase pertumbuhan biji, jumlah daun dan tinggi tanaman pada penelitian ini tergantung dari media tumbuh (Tabel 1). Variasi angka rata-rata persen tumbuh tersebut didukung oleh pendapat Lakitan (1995) yang menyatakan bahwa setiap tanaman mempunyai respons yang berbeda-beda terhadap pemberian perlakuan. Pemakaian zat pengatur tumbuh tersebut pertama-tama ditujukan untuk merangsang pertumbuhan tanaman tingkat tinggi. Penelitian pengaruh zat pengatur tumbuh (auksin dan sitokinin) pada kultur aren (Arenga pinnata (Wumrb) Merr.) menunjukkan bahwa kombinasi konsentrasi $1,0 \mathrm{mg} \mathrm{L}^{-1} \mathrm{NAA}$ dan $1,0 \mathrm{mg} \mathrm{L}^{-1}$ BAP mampu menghasilkan presentase hidup eksplan tertinggi dan persentase eksplan yang mernbentuk kalus (Putih et.al., 2003). Selain itu zat tersebut pada konsentrasi rendah dapat mempengaruhi fungsi fisiologis tanaman yaitu mempengaruhi pembukaan stomata, translokasi dan serapan hara tanaman, selain itu pada penelitian lainnya juga menyatakan bahwa penggunaan ZPT memacu perakaran pada stek dan memacu jumlah akar (Jimnes \& Banger, 2001).

\section{Persen Tumbuh}

Tanaman paling cepat tumbuh ditunjukkan oleh biji yang ditanam di media kompos, kemudian disusul oleh media pasir sebagai kontrol, selanjutnya di tanah Latosol dan terkhir adalah media PMK (Tabel 1).

Tabel 1. Pengaruh pemberian zat pengatur tumbuh tanaman pada berbagai media pada pertumbuhan biji palem putri umur tiga bulan.

\begin{tabular}{lccc}
\hline \multicolumn{1}{c}{ Media } & $\begin{array}{c}\text { Persen } \\
\text { tumbuh }\end{array}$ & $\begin{array}{c}\text { Jumlah } \\
\text { Daun }\end{array}$ & $\begin{array}{c}\text { Tinggi } \\
\text { Tanaman }\end{array}$ \\
\hline Pasir (Kontrol) & 70 & 0,43 & 6,07 \\
Kompos & 80 & 0,47 & 10,33 \\
Latosol & 63 & 0,40 & 6,97 \\
PMK & 33 & 0,17 & 2,43 \\
\hline
\end{tabular}

Penelitian ini sejalan dengan penelitian yang serupa pada tanaman mengkudu, menjelaskan bahwa kompos berperan penting dalam perkecambahan dan pertumbuhan bibit. Benih mengkudu yang ditanam di media campuran tanah pasir kompos dan di media pasir kompos memperlihatkan perkecambahan dan pertumbuhan yang baik dan merata dengan persentase perkecambahan mencapai $90 \%$ (Lendri, 2003).

\section{Pertumbuhan daun}

Pada waktu bibit masih muda, pertumbuhan daun hanya dua (2) saja. Biasanya daun tumbuh setelah 2 minggu tumbuhnya tunas. Dengan demikian tumbuhnya daun tidak serempak tetapi tergantung pada pertumbuhan tunasnya. Rata-rata jumlah daun tertinggi $(0,47)$ ditunjukkan oleh media kompos sedang terendah ( 0,17 helai) ditunjukkan oleh media PMK (Tabel 1.). Peran ompos pada pertumbuhan daun telah diteliti pada tanaman ramin. Perkecambahan biji ramin sampai terbentuknya pasangan daun kedua di media berlangsung selama 26 hari, lebih singkat daripada perkembangan di media lainnya (Rachman \& Utami, 2006)

\section{Tinggi tanaman}

Tinggi tanaman bervariasi tergantung pada umur tanamannya. Pada waktu biji baru tumbuh, tinggi tunas rata-rata $1 \mathrm{~cm}$ kemudian bertambah dengan semakin meningkatnya umur tanaman. Hal ini berbeda-beda tingginya dan tergantung pada media yang digunakan. Tinggi tanaman diukur dari permukaan tanah sampai bagian batang tertinggi. Tinggi tanaman tertinggi ditunjukkan oleh bibit yang ditanam pada media kompos $(10,33 \mathrm{~cm})$, dan terendah $(2,43 \mathrm{~cm})$ ditunjukkan oleh bibit yang ditanam di media Podsolik merah kuning (Tabel 1 dan Gambar 2). Berturut turut tinggi tanaman dari yang tertinggi ke yang paling rendah adalah media kompos, pasir, latosol dan PMK.

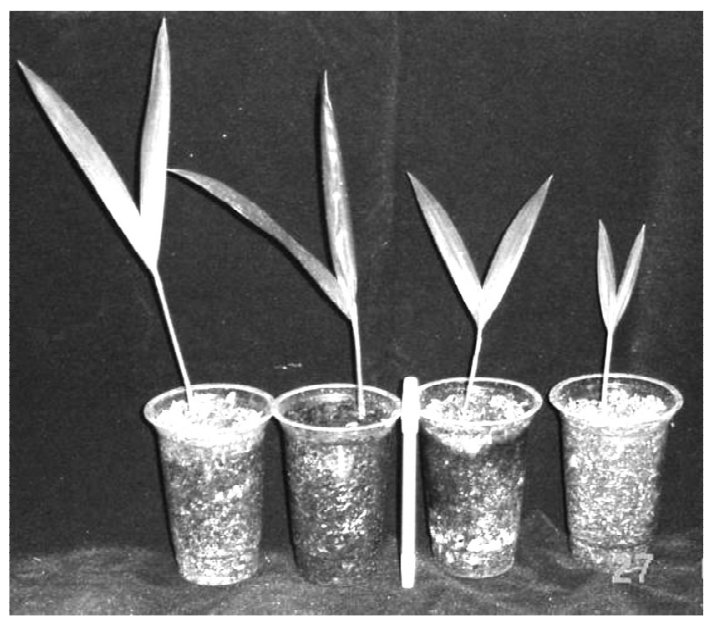

Gambar 2. Tinggi tanaman pada berbagai media pada berbagai media tanah. Dari kiri ke kanan kompos, pasir, latosol dan PMK. 


\section{Panjang akar}

Akar terpanjang ditunjukkan oleh biji yang dikecambahkan pada media kompos, kemudian media pasir, selanjutnya oleh media Latosol dan terakhir PMK (Gambar 3). Rata-rata panjang akar terpanjang ditunjukkan oleh biji yang dikecambahkan pada media kompos yaitu 27,6 cm, sedang terpendek yaitu ditunjukkan oleh biji yang dikecambahkan Pada media PMK yaitu 7,6 cm (Gambar 3). Dengan menambahkan subsoil, Suherman et al. (2007) telah membuktikan bahwa kompos berperan penting dalam pembibitan tanaman kelapa sawit. Kompos mengandung sejumlah unsur hara makro $\mathrm{N}, \mathrm{P}$ dan $\mathrm{K}$ serta $\mathrm{C} / \mathrm{N}$ sekitar yang relatif rendah sehingga degradasi mikrobiologis dapat menyediakan unsur hara.

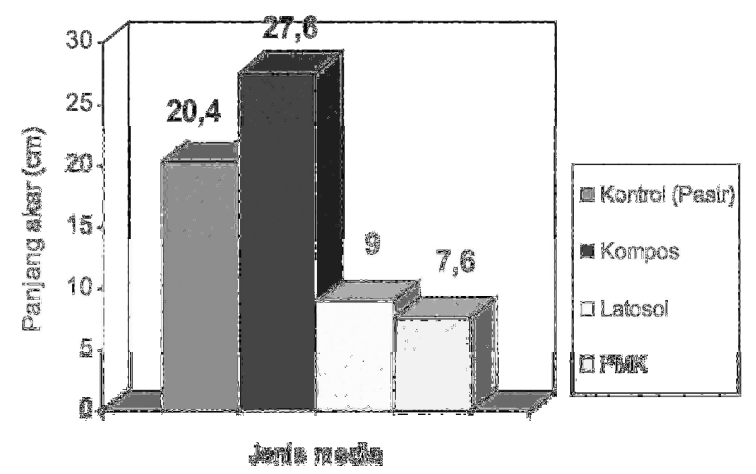

Gambar 3. Pengaruh berbagai dosis media terhadap pertumbuhan akar Palem Putri

Dari data hasil pengamatan, persentase berkecambah tertinggi ditunjukkan oleh biji yang dikecambahkan pada media kompos, selanjutnya berturut turut adalah media pasir, tanah Latosol dan PMK, demikian pula pada parameter pertumbuhan yang lain. (Tabel 1). Angka rataan yang diperoleh, menunjukkan bahwa angka tersebut sangat bervariasi dan pada umumnya angka tertinggi ditunjukkan oleh bibit yang ditanam di media kompos dan terendah ditunjukkan oleh bibit yang ditanam di media PMK hal ini ditunjukkan oleh semua parameter yang diamati. Hal ini sesuai dengan hara yang dikandung oleh tanah tersebut.

Kompos yang mengandung banyak unsur hara dan bersifat sarang, paling banyak meningkatkan persentase kecambah. Pada media ini persen berkecambah biji paling tinggi yaitu $80 \%$ (Tabel 1) dan pertumbuhan bibit pun paling subur (Gambar 2), dibandingkan dengan media yang lain yang digunakan. Pasir yang teksturnya sarang meskipun miskin akan unsur hara ternyata paling mudah ditembus oleh akar sehingga persen tumbuh biji juga cukup tinggi yaitu $70 \%$ (Tabel 1) tetapi tinggi tanaman lebih rendah daripada tanaman yang ditanam di media kompos (Gambar 2). Pada fase perkecambahan pada waktu daun belum berfungsi untuk fotositesis, tanaman masih menggunakan sediaan makanan dari biji sehingga sampai akhir penelitian, serapan unsur hara oleh bibit belum sepenuhnya tergantung dari unsur hara pada media tumbuh (Sutopo, 1984).

Tanah Latosol dan PMK bersifat masam (Subagio et al. 2000). Latosol mudah menyerap air, mengandung liat lebih dari $60 \%$, berstruktur remah tetapi miskin unsur hara nitrogen, fosfor maupun kalium (Darmawijaya, 1997). Persen berkecambah pada media ini masih cukup tinggi yaitu $63 \%$ (Tabel 1) serta pertumbuhannya Lebih baik dibandingkan podsolik merah kuning (Gambar 2). PMK adalah tanah dengan produktivitas rendah dan berliat (Idwar et al, 2003) sehingga sulit meluluskan air sehingga jumlah pori aerob yang mendorong serapan unsur hara akan menurun. Tanah PMK kaya akan Al yang menyebabkan kemasaman tinggi (Hardjowigeno, 1992). Kemasaman tanah latosol pada penelitian ini adalah 5 sedangkan tanah Podzolic merah kuning adalah 4. Pada $\mathrm{pH}$ yang asam kedua jenis tanah tersebut banyak mengandung Al sehingga dapat meracuni tanaman (Norsamsi, 2006). Oleh karena sifatnya yang demikian, maka pertumbuhannya lambat dan persentase perkecambahan hanya $33 \%$ (Tabel 1) dengan tinggi tanamanterendah (Gambar 2) serta panjang akar (Gambar 3) paling rendah. Pada media yang berbeda yaitu media cair dan media padat misalnya air dengan kompos karena kompos mengandung unsur hara lebih banyak dari pada air (Musnamar, 2003) maka media kompos hasilnya lebih baik. Pada media padat yang kurang unsur hara hasilnya lebih rendah.

\section{SIMPULAN}

Dibandingkan dengan pasir, tanah jenis Latosol maupun Podsolik Merah Kuning, media untuk perkecambahan dan pertumbuhan bibit aren terbaik adalah kompos. Hasil studi menunjukkan bahwa perkecambahan biji paling cepat di media kompos dan paling lambat di tanah Podsolik Merah Kuning. Jumlah daun, tinggi tanaman dan panjang akar terbaik diperlihatkan oleh bibit yang ditanam pada media kompos. 


\section{UCAPAN TERIMA KASIH}

Ucapan terima kasih disampaikan kepada Kepala Kebun Plasma Nutfah Tumbuhan dan Hewan Puslit LIPI yang telah menyediakan tempat sehingga penelitian ini terlaksana dengan baik.

\section{DAFTAR PUSTAKA}

Darmawijaya, MI. 1997. Klasifikasi Tanah. Dasar teori bagi peneliti dan pelaksana pertanian di Indonesia. Fakultas Pertanian Universitas Gajahmada. Yogyakarta. Gajah Mada University Press. 411 hal.

Hardjowigeno, S.1992. Imu Tanah Edisi Ketiga.PT Media Utama Sarana Perkasa. Jakarta 233 hal.

Hartmann, HT, DE Kester and FD Davies.1990. Plant Propagation, Principle and Practices. Prentice-Hall International Ink. New Jersey. $647 \mathrm{pp}$.

Idwar, Rosmini, dan J Sulistiyo. 2003. Netralisasi kandungan Aluminium (Al) tanah podzolik merah kuning dengan pemberian batuan fosfat alam dan bahan organik untuk pertumbuhan dan produksi padi gogo (Oryza sativa L).

www.unri.ac.id/jurnal_natur/vol17(2)

Idwar.pdf. Diakses tanggal 10 Juli 2010.

Lakitan, B. 1995. Hortikultura, Teori, Budidaya dan Pasca Panen. PT Raja Gravindo Persada. Jakarta.219 pp.

Lendri, S. 2003. Teknik pembibitan mengkudu pada berbagai media. Buletin Teknik Pertanian. 8: 4-7

Musnamar, EI. 2003. Pembuatan dan Aplikasi Pupuk Organik Padat. Seri Agrotekno. CV Penebar Swadaya. Jakarta.70 pp.
Noad,T and A Birnie. 1992. Trees of Kenya. PO Box 40034, Nairobi, 306 pp.

Norsamsi, D. 2006. Kenbutuhan hara kalium tanaman kedelai di tanah ultisol. Jurnal Ilmu Tanah dan Lingkungan. Fakultas Pertanian, Universitas Gajah Mada Yogjakarta. 6(2): 71-81.

Poincelot.1979. Horticuture. Principle and Practical Application. Englewood Cliffs. NJ. Prentice Hall. 200 pp.

Rachman, E dan NW Utami. 2006. Pola perkecambahan ramin (Gonystylus bancanus) dan efektivitas komposisi media tanam. Berita Biologi. 8: 37-43.

Putih, R, B Satria, dan R Thaib. 2003. Upaya perbanyakan vegetatif enau (Arenga pinnata (Wumrb) Merr.) melalui regenerasi tunas secara in vitro. Stigma. 11: 208-212.

Norsamsi. 2006. Kebutuhan hara kalium tanaman kedelai di tanah Ultisol. Jurnal Ilmu Tanah Dan Lingkungan. 6: 71-81.

Suherman, C, A Nuraini dan S Rosniawaty. 2007. Pemanfaatan cendawan mikoriza arbuskular serta media campuran subsoil dan kompos pada pembibitan kelapa sawit (elaeis guineensis) kultivar Sungai Pancur 2. http://pustaka.unpad.ac.id/archives/28523/\# diakses 7 Februari 2010.

Sutopo, L.1984. Teknologi Benih. CV Rajawali. Jakarta.243 hal.

Warintek, 2010. Palem Putri. Menteri Negara Ristek. Budidaya Teknologi Tepat Guna. Sistem Informasi Managemen Pembangunan di Pedesaan. Bappenas.

http://www.iptek.net.id/ind/warintek/?mnu $=6 \& \mathrm{ttg}=2 \& \mathrm{doc}=2 \mathrm{~b} 8$ Diakses terbit 2010. 